\title{
Multiplex polymerase chain reaction as an improved method for screening Histoplasma capsulatum mating types
}

\author{
Fernando Almeida-Silva1, Leonardo Silva Barbedo',2, Maria Lucia Taylor ${ }^{3}$, \\ Mauro de Medeiros Muniz ${ }^{1}$, Allan Jefferson Guimarães ${ }^{4}$, Rosely Maria Zancopé-Oliveira1/+ \\ ${ }^{1}$ Fundação Oswaldo Cruz-Fiocruz, Instituto Nacional de Infectologia Evandro Chagas, Laboratório de Micologia, Setor de Imunodiagnóstico, \\ Rio de Janeiro, RJ, Brasil \\ ${ }^{2}$ Universidade Federal do Amazonas, Instituto de Saúde e Biotecnologia, Coari, AM, Brasil \\ ${ }^{3}$ Universidad Nacional Autónoma de México, Facultad de Medicina, Departamento de Microbiología-Parasitología, DF, México \\ ${ }^{4}$ Universidade Federal Fluminense, Instituto Biomédico, Departamento de Microbiologia e Parasitologia, Niterói, RJ, Brasil
}

Histoplasmosis is a systemic mycosis infection caused by Histoplasma capsulatum, a heterothallic ascomycete. The sexual reproduction of this fungus is regulated by the mating type (MAT1) locus that contains MAT1-1 and MAT1-2 idiomorphs, which were identified by uniplex polymerase chain reaction (PCR). This study aimed to optimise single-step multiplex PCR for the accurate detection of the distinct mating types of $H$. capsulatum. Among the 26 isolates tested, 20 had MAT1-1 genotype, while six showed MAT1-2 genotype, in agreement with the uniplex PCR results. These results suggest that multiplex PCR is a fast and specific tool for screening $H$. capsulatum mating types.

Key words: mating type - MAT1 - Histoplasma capsulatum - multiplex PCR

The significance of sexual selection, the component of natural selection associated with variation in mating success, is well established for the evolution of animals and plants but not fungi. Mating types determine genetic compatibility among fungal gametes and are important for sexual selection in two respects. First, genes at the mating-type loci regulate different aspects of mating and thus may be subject to sexual selection. Second, for sexual selection, not only the two sexes (or sex roles) but also the mating types can form classes, wherein the members compete for access to members of the other class. ${ }^{(1)}$ In ascomycetes, the genes of the two mating types are not homologous and are therefore referred to as idiomorphs. ${ }^{(2)}$ Depending on the species, the genes at the mating-type loci may regulate functions that operate during mating such as extracellular signalling, ${ }^{(3,4)}$ cell fusion, ${ }^{(5)}$ inheritance of cytoplasmic genes, ${ }^{(6)}$ and establishment of a diploid or heterokaryotic individual. ${ }^{(7)}$ In addition, these genes may regulate cell division, ${ }^{(8)}$ sexual reproduction, ${ }^{(9)}$ and virulence ${ }^{(10)}$ after zygote formation.

Mating loci have been identified in other filamentous ascomycete fungi, including Neurospora crassa, ${ }^{(11,12)} \mathrm{As}$ pergillus nidulans, ${ }^{(13)}$ and A. fumigatus. ${ }^{(14)}$ Mating process has a potential role in the virulence of human pathogens. Recombination between two strains may result in a new strain with increased virulence. ${ }^{(15)}$ The pathogenic fungus Histoplasma capsulatum has been shown to undergo recombination; ${ }^{(16,17)}$ however, little is known about its mating process on molecular levels.

doi: $10.1590 / 0074-02760180340$

Financial support: CNPq (350338/2000-0), FAPERJ (E-26/203.076/2016) to RMZ-O.

+ Corresponding author: rosely.zancope@ini.fiocruz.br

Received 20 July 2018

Accepted 17 August 2018
H. capsulatum is a heterothallic ascomycete that has anamorph and teleomorph stages. The anamorph stage or asexual reproduction occurs upon hyphal fragmentation or conidium production in a specialised hypha or by budding in yeasts. The sexual or teleomorph stage occurs by the conjugation of two compatibility types, encoded by the locus $M A T 1$, and contains two idiomorphic regions as follows: MAT1-1 (alpha-domain transcription factor) and MAT1-2 [high-mobility-group (HMG) transcription factor] also known as - and +, respectively. ${ }^{(10,18)}$ It has been suggested that strains of each mating type are not equally represented among clinical isolates of $H$. capsulatum, with a current ratio of 7:1 (MAT1-1:MAT1-2); however, environmental samples exhibit a 1:1 ratio of the two mating types. ${ }^{(19)}$ Experiments with murine infection revealed that the two mating types showed no difference in their virulence potential. ${ }^{(20)}$ A recent study using African clinical isolates showed a ratio of 1:3 (MAT1-1:MAT1-2), contradicting other results. ${ }^{(21)}$

Molecular methods are routinely applied for the identification of mating types in fungi since phenotypic methods are unpredictable; fungi such as $H$. capsulatum lose the ability to mate in vitro within a short period of time. ${ }^{(22)}$ Among the molecular methods, uniplex polymerase chain reaction (PCR) using specific primers targeting idiomorphic regions MAT1-1 and MAT1-2 is the most common technique. ${ }^{(15)}$ A recent study using this technique compared the frequency of the locus MAT1 in Mexican and Brazilian isolates and found mating types in 14 Mexican isolates (four MAT1-1 and 10 MAT1-2) and 14 Brazilian isolates (all were MAT1-1). ${ }^{(23)}$

Until now, uniplex PCR has been applied to detect mating types in $H$. capsulatum. ${ }^{(18)}$ Here, we evaluate a multiplex PCR format for the ability to differentiate between MAT1-1 and MAT1-2 in H. capsulatum strains and compare the results with those of uniplex PCR using the same primer sets (Table I). 
We used the sequences of the two reference strains from GenBank, G217B: MAT1-1 (accession number EF433757, ATCC 26032) and G186A: MAT1-2 (accession number EF433756, ATCC 26029) to perform an in silico multiplex PCR assay using the FastPCR v.6.0 software with two sets of primers (Table I). We observed that the primers specific for the control reference strains generated fragments of 440 and $528 \mathrm{bp}$, as previously described. ${ }^{(15)}$

To confirm our in silico observations, genomic DNA was extracted from the yeast phase of reference strains, ${ }^{(24)}$ and multiplex PCR was performed with the primers previously described (Table I) in a final volume of $50 \mu \mathrm{L}$. Each reaction mixture contained 75 ng of DNA, 1X PCR buffer $[10 \mathrm{mM}$ Tris- $\mathrm{HCl}(\mathrm{pH} 8.4)$ and $50 \mathrm{mM}$ potassium chloride $(\mathrm{KCl})], 1.5 \mathrm{mM}$ magnesium chloride $\left(\mathrm{MgCl}_{2}\right)$ (Thermo Scientific TM, Brasil), $200 \mu \mathrm{M}$ of each dNTP (Thermo Scientific TM, USA), 2.5 U platinum DNA Taq polymerase (Thermo Scientific TM, Brasil), and 50 ng of each primer. Multiplex PCR was performed on a Bio-Rad C1000 Thermal Cycler with the following program: Initial denaturation at $95^{\circ} \mathrm{C}$ for $3 \mathrm{~min}$, followed by 35 cycles of denaturation for $30 \mathrm{~s}$ at $95^{\circ} \mathrm{C}$, annealing for $30 \mathrm{~s}$ at $58^{\circ} \mathrm{C}$, extension for $1 \mathrm{~min}$ and $30 \mathrm{~s}$ at $72^{\circ} \mathrm{C}$, and a final extension step at $72^{\circ} \mathrm{C}$ for $10 \mathrm{~min} .^{(23)}$ The samples were analysed by electrophoresis on a $1 \%$ agarose gel at $100 \mathrm{~V}$ for approximately $1 \mathrm{~h}$. The gel was stained with ethidium bromide $(0.5 \mu \mathrm{g} / \mathrm{mL})$ and the amplicons were observed and photographed under UV light $(280 \mathrm{~nm})$.

Multiplex PCR reproducibility was confirmed by repeating the assays at least thrice under same conditions. Three different conditions evaluated in silico to standardise this protocol were as follows: (i) reference strain G186A DNA idiomorph (MAT1-2); (ii) a DNA mix of both reference strains (MAT1-2 + MAT1-1); and (iii) reference strain G217B DNA idiomorph (MAT1-1) (Fig. 1).

The results of multiplex PCR showed DNA fragments of 440 and $528 \mathrm{bp}$ for MAT1-1 and MAT1-2, respectively. A clear resolution of bands obtained for the mixed samples allowed distinction between the two idiomorphic regions. This enabled us to perform classification in both the reference samples and the sample sets studied (Fig. 2).

Uniplex and multiplex PCR were performed following the above protocol for 26 Brazilian $H$. capsulatum isolates from the Fungal Culture Collection of Evandro Chagas National Institute of Infectious Diseases, Oswaldo Cruz Foundation (INI/Fiocruz) (Table II). Of these isolates, 14 were previously characterised as MATI-1 by uniplex $\mathrm{PCR}^{(23)}$ and were re-evaluated by uniplex and multiplex PCR. All of these isolates, previously determined as MAT1-1 idiomorph by uniplex PCR, ${ }^{(23)}$ displayed the same genotype by both methods. However, analysis of the 26 Brazilian isolates showed that MAT11 genotype was predominant and represented $77 \%$ (20) of the isolates, whereas $23 \%$ (6) of the isolates were of MAT1-2 genotype. Overall, there was $100 \%$ agreement between uniplex and multiplex PCR results for mating type characterisation (Table II).

Here, we demonstrated a significant improvement in the molecular determination of mating types of $H$. capsulatum by comparing the results between the developed protocol and the previously known methodology. ${ }^{(15)}$ Mul-
TABLE I

Primers for the multiplex polymerase chain reaction ${ }^{(15)}$

Primers Sequence

MAT1-1 S (Forward) 5'-CGTGGTTAGTTACGGAGGCA-3'

MAT1-1 AS (Reverse) 5'-TGAGGATGCGAGTGATGGGA-3'

MAT1-2 S (Forward) 5'-ACACAGTAGCCCAACCTCTC-3'

MAT1-2 AS (Reverse) 5'-TCGACAATCCCATCCAATACCG-3'

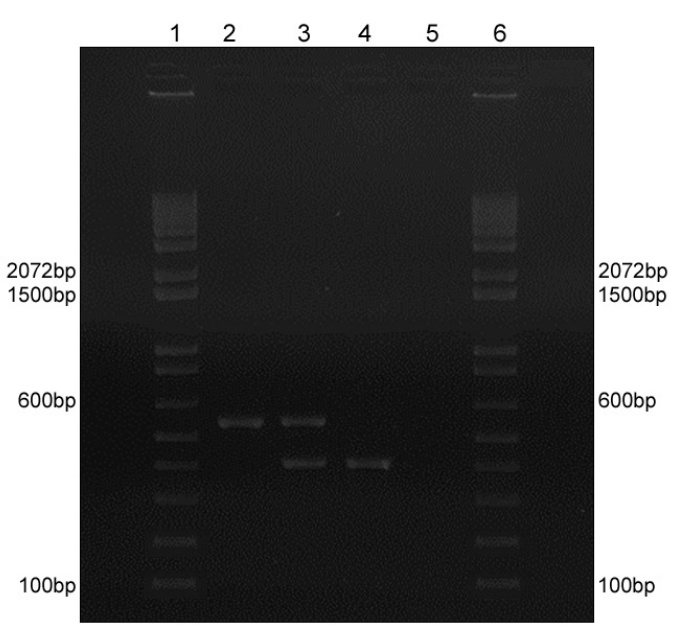

Fig. 1: representative multiplex polymerase chain reaction profiles of Histoplasma capsulatum mating types. (1 and 6) Molecular marker 100-bp DNA ladder (Thermo Scientific); (2) reference strain G186A (ATCC 26029) MAT1-2 corresponding to $528 \mathrm{bp}$; (3) reference strains G186A (higher fragment with $528 \mathrm{bp}$ ) and G217B (lower fragment with 440 bp); (4) reference strain G217B (ATCC 26032) MAT1-2 corresponding to $440 \mathrm{bp}$; (5) negative control.

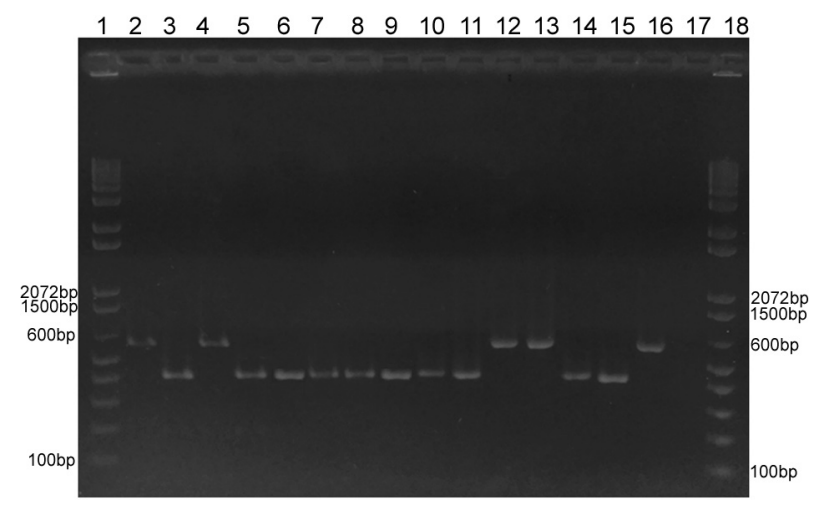

Fig. 2: representative gel electrophoresis of multiplex polymerase chain reaction profiles from 13 studied isolates and reference strains. Lanes 1 and $18=100$-bp DNA ladder (Thermo Scientific); lanes 2, 4, 12 , and 13 corresponding to isolates $128 \mathrm{H}, \mathrm{HC} 40039$, INI $01 / 16$, and IPEC 01/12, respectively, classified as mating type 1-2; lanes 3, 5, 6, $7,8,9,10,11$, and 14 corresponding to the isolates 39439 , INI $02 / 16$, 18H, 37307, M396/08, M487/08, IGS19, RPS51, and IPEC 02/13, respectively, classified as mating type 1-1; lane $15=$ reference strain G217B mating type 1-1 (ATCC 26032); lane 16 = reference strain G186A mating type 1-2 (ATCC 26029); lane 17 = negative control. 
TABLE II

Mating types of 26 Brazilian Histoplasma capsulatum isolates

\begin{tabular}{|c|c|c|c|c|}
\hline \multirow[b]{2}{*}{ Isolate } & \multirow[b]{2}{*}{ Source } & \multirow[b]{2}{*}{ Location } & \multicolumn{2}{|c|}{ Mating type } \\
\hline & & & $\begin{array}{l}\text { Uniplex } \\
\text { PCR }\end{array}$ & $\begin{array}{l}\text { Multiplex } \\
\text { PCR }\end{array}$ \\
\hline $18 \mathrm{H}$ & Human & RJ & MAT1-1 & MAT1-1 \\
\hline 37307 & Human & $\mathrm{RJ}$ & MAT1-1 & MAT1-1 \\
\hline $247 \mathrm{BL}$ & Human & MS & MAT1-1 & MAT1-1 \\
\hline M396/08 & Animal & SP & MAT 1-1 & MAT 1-1 \\
\hline M1084/08 & Animal & SP & MAT1-1 & MAT1-1 \\
\hline M487/08 & Animal & SP & MAT1-1 & MAT1-1 \\
\hline M975/08 & Animal & SP & MAT1-1 & MAT1-1 \\
\hline $\mathrm{AC} 05$ & Soil & RJ & MAT1-1 & MAT1-1 \\
\hline TI01 & Soil & $\mathrm{RJ}$ & MAT1-1 & MAT1-1 \\
\hline IGS19 & Soil & RJ & MAT1-1 & MAT1-1 \\
\hline RPS51 & Soil & $\mathrm{RJ}$ & MAT1-1 & MATl-1 \\
\hline $\mathrm{CO} 2$ & Soil & RJ & MAT1-1 & MAT1-1 \\
\hline $\mathrm{CO} 4$ & Soil & $\mathrm{RJ}$ & MAT1-1 & MAT1-1 \\
\hline IGS4/5 & Soil & RJ & MAT1-1 & MAT1-1 \\
\hline $129 \mathrm{H}$ & Human & RJ & MAT1-2 & MAT1-2 \\
\hline 39942 & Human & $\mathrm{RJ}$ & $M A T 1-2$ & MAT1-2 \\
\hline HC40039 & Human & RJ & MAT1-2 & MAT1-2 \\
\hline INI 01/16 & Human & $\mathrm{RJ}$ & MAT1-2 & MAT1-2 \\
\hline INI 06/16 & Human & $\mathrm{RJ}$ & MAT1-2 & MAT1-2 \\
\hline IPEC 01/12 & Human & RJ & MAT1-2 & MAT1-2 \\
\hline 2090603 & Human & $\mathrm{RJ}$ & MAT1-1 & MAT1-1 \\
\hline 39439 & Human & $\mathrm{RJ}$ & MAT1-1 & MAT1-1 \\
\hline HC 18 & Human & $\mathrm{RJ}$ & MAT1-1 & MAT1-1 \\
\hline INI 02/16 & Human & RJ & MAT1-1 & MAT1-1 \\
\hline INI 03/16 & Human & $\mathrm{RJ}$ & MAT1-1 & MAT1-1 \\
\hline IPEC 02/13 & Human & $\mathrm{RJ}$ & MAT1-1 & MAT1-1 \\
\hline
\end{tabular}

MAT1-1: mating type 1-1; MAT1-2: mating type 1-2; MS: Mato Grosso do Sul; PCR: polymerase chain reaction; RJ: Rio de Janeiro; SP: São Paulo.

tiplex PCR assay showed accurate and specific results, as evident from the similarity with uniplex PCR results. (23) Several reports are focused on the development of simple and low-cost methodologies as well optimisation of existing molecular methods. New approaches or modifications have already been proposed. For instance, PCR in multiplex format for laboratory diagnosis of Pneumocystis jirovecii, H. capsulatum, and Cryptococcus neoformans/C. gattii( ${ }^{(25)}$ and detection of C. parapsilosis complex species has been reported. ${ }^{(26)}$

This work describes the assessment of mating types of $H$. capsulatum by genomic DNA amplification with a single PCR reaction. The multiplex PCR profiles were highly informative, generated clearly distinct banding patterns for each MAT1 idiomorph, and allowed easy differentiation. This proposed technique is simple, reliable, rapid, cheap, and requires less technical effort.

In conclusion, multiplex PCR may be performed for the accurate identification of $H$. capsulatum mating types in a simple one-step reaction. There are two re- markable points demonstrated in this work. First, this identification process may be completed in a multiplex PCR step followed by electrophoresis. Second, the method saves time, reagents, and cost. We suggest that the introduction of this method in research laboratories for mating type identification may be relevant for epidemiological surveillance and virulence studies. This method may be of real importance for gathering relevant information in H. capsulatum culture databank.

\section{AUTHORS' CONTRIBUTION}

FA-S and LSB were the executors of the molecular biology experiments and participated in the conception, design, and drafting of the manuscript; M-LT, MMM, and AJG participated in the interpretation of the results and writing of the manuscript; RMZ-O conceptualised the project, supervised experiments, and performed final revision of the manuscript. All authors read and approved the final manuscript. The authors declare no conflict of interest.

\section{REFERENCES}

1. Nieuwenhuis BPS, Aanen DK. Sexual selection in fungi. J Evol Biol. 2012; 25(12): 2397-411.

2. Metzenberg R, Glass N. Mating type and mating strategies in Neurospora. BioEssays. 1990; 12(2): 53-9.

3. Kothe E. Sexual attraction: on the role of fungal pheromone/receptor systems (A review). Acta Microbiol Immunol Hung. 2008; 55(2): 125-43.

4. Raudaskoski M, Kothe E. Basidiomycete mating type genes and pheromone signaling. Eukaryot Cell. 2010; 9(6): 847-59.

5. Glass NL, Jacobson DJ, Shiu PKT. The genetics of hyphal fusion and vegetative incompatibility in filamentous ascomycete fungi. Annu Rev Genet. 2000; 34: 165-86.

6. Yan Z, Xu JP. Mitochondria are inherited from the MATa parent in crosses of the basidiomycete fungus Cryptococcus neoformans. Genetics. 2003; 163 (4): 1315-25.

7. Crowe LK. Competition between compatible nuclei in the establishment of a dikaryon in Schizophyllum commune. Heredity. 1963; 18: 525-33.

8. Raper CA. B-mating-type genes influence survival of nuclei separated from heterokaryons of Schizophyllum. Exp Mycol. 1985; 9(2): 149-60.

9. Van Heeckeren WJ, Dorris DR, Struhl K. The mating-type proteins of fission yeast induce meiosis by directly activating mei3 transcription. Mol Cell Biol. 1998; 18(12): 7317-26.

10. Kwon-Chung KJ, Bennett JE. Histoplasmosis. In: Medical mycology. Pennsylvania: Lea \& Febiger; 1992. p. 464-513.

11. Glass NL, Grotelueschen J, Metzenberg RL. Neurospora crassa A mating-type region. Proc Natl Acad Sci USA. 1990; 87(13): 4912-6.

12. Staben C, Yanofsky C. Neurospora crassa a mating-type region. Proc Natl Acad Sci USA. 1990; 87(13): 4917-21.

13. Dyer PS, Paoletti M, Archer DB. Genomics reveals sexual secrets of Aspergillus. Microbiology. 2003; 149(Pt): 2301-3.

14. Paoletti M, Rydholm C, Schwier EU, Anderson MJ, Szakacs G, Lutzoni F, et al. Evidence for sexuality in the opportunistic fungal pathogen Aspergillus fumigatus. Curr Biol. 2005; 15(13): 1242-8.

15. Bubnick M, Smulian AG. The MAT1 locus of Histoplasma capsulatum is responsive in a mating type-specific manner. Eukaryot Cell. 2007; 6(4): 616-21. 
16. Carter DA, Burt A, Taylor JW, Koenig GL, White TJ. Clinical isolates of Histoplasma capsulatum from Indianapolis, Indiana, have a recombining population structure. J Clin Microbiol. 1996; 34(10): $2577-84$.

17. Kasuga T, Taylor JW, White TJ. Phylogenetic relationships of varieties and geographical groups of the human pathogenic fungus Histoplasma capsulatum Darling. J Clin Microbiol. 1999; 37(3): 653-63.

18. Muniz MM, Sousa CN, Oliveira MME, Pizzini CV, Almeida MA, Rodríguez-Arellanes G, et al. Sexual variability in Histoplasma capsulatum and its possible distribution: what is going on? Rev Iberoam Micol. 2014; 31(1): 7-10.

19. Kwon-Chung KJ, Weeks RJ, Larsh HW. Studies on Emmonsiella capsulata (Histoplasma capsulatum). II. Distribution of the two mating types in 13 endemic states of the United States. Am J Epidemiol. 1974; 99(1): 44-9.

20. Kwon-Chung KJ. Virulence of the two mating types of Emmonsiella capsulata and the mating experiments with Emmonsiella capsulata var. duboisii. In: C de Vroey, R Vanbreuseghem, editors. Sexuality and pathogenicity of fungi. Paris: Masson; 1981. p. 48-56.

21. Valero C, Gago S, Monteiro MC, Alastruey-Izquierdo A, Buitrago MJ. African histoplasmosis: new clinical and microbiological insights. Med Mycol. 2018; 56(1): 51-9.
22. Kwon-Chung KJ. Studies on Emmonsiella capsulata. I. Heterothallism and development of the ascocarp. Mycologia. 1973; 65(1): 109-21.

23. Rodriguez-Arellanes G, Sousa CN, Muniz MM, Ramirez JA, Pizzini CV, Almeida MA, et al. Frequency and genetic diversity of the MAT1 locus of Histoplasma capsulatum isolates in Mexico and Brazil. Eukaryot Cell. 2013; 12(7): 1033-8.

24. Muniz MM, Tavares PMS, Meyer W, Nosanchuk JD, Zancope-Oliveira RM. Comparison of different DNA-based methods for molecular typing of Histoplasma capsulatum. Appl Environ Microbiol. 2010; 76(13): 4438-47.

25. Gago S, Esteban C, Valero C, Zaragoza O, de la Bellacasa JP, Buitrago MJ. A multiplex real-time PCR assay for identification of Pneumocystis jirovecii, Histoplasma capsulatum, and Cryptococcus neoformans/Cryptococcus gattii in samples from AIDS patients with opportunistic pneumonia. J Clin Microbiol. 2014; 52(4): 1168-76.

26. Asadzadeh M, Ahmad S, Hagen F, Meis JF, Al-Sweih N, Khan Z. Simple, low-cost detection of Candida parapsilosis complex isolates and molecular fingerprinting of Candida orthopsilosis strains in Kuwait by ITS region sequencing and amplified fragment length polymorphism analysis. PLoS One. 2015; 10(11): e0142880. 